\title{
A MACHINE LEARNING APPROACH TOWARDS DETERMINING THE OPENNESS OF URBAN PLAZA
}

\author{
MD. SHARIFUL ALAM ${ }^{1}$ \& CHOWDHURY ALI IMAM ${ }^{2}$ \\ 1, Department of Architecture, Bangladesh University of Engineering and Technology (BUET), Dhaka, Bangladesh \\ ${ }^{2}$ Department of Architecture, Military Institute of Science and Technology (MIST), Dhaka, Bangladesh

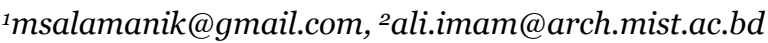

\begin{abstract}
The design of urban plaza is guided by the principle of $\mathrm{D} / \mathrm{H}$ ratio where $\mathrm{D}$ denotes distance and $\mathrm{H}$ denotes building façade height which provides a quantitative measure of the enclosure. Plaza has been considered as an outdoor room and the buildings are the walls. But these urban walls are not continuous. Connecting roads, voids between buildings, the variation of building heights, and the omission of building on any side of the plaza affect openness. So, maintaining the same $\mathrm{D} / \mathrm{H}$ ratio the sense of enclosure can be varied. This paper aims at determining the inter-relation of openness with distance and height for better understanding the idea of enclosure of urban plaza using machine learning algorithms. Machine learning can be used to determine the non-linear relationship between multiple variables. The variables $\mathrm{D}$ and $\mathrm{H}$ are set by the author where the perforation of the surrounding elevation varied, then respondents were asked to rate the degree of openness of the plazas based on their virtual journey using a head-mounted Virtual Reality (VR) display. Utilizing their responses an inter-relation among the parameters is determined by training up an artificial Neural Network (ANN) to predict the openness of any plaza. This can be used as a process of analyzing user experience of urban plazas.
\end{abstract}

Keywords: Machine learning, Virtual reality, D/H ratio, Neural Network, urban plaza

\section{Introduction}

The urban plaza is one sort of urban open space that works as a center of social and economic activity as well as a focal point for community congregation (Liu, 2013). Urban plazas are considered as the most valuable places in a city that foster various interactions among city dwellers. (Dillard, et al., 2008)

For this great importance of urban plaza, a great number of efforts were given to understand the appropriate scale and human perception of the plaza space by architects and urban designers. Theorists tried to measure them by analyzing the spatial arrangement or the physical formation of the place. One established way to measure the quality of urban plaza is to quantify the sense of the enclosure by measuring the $\mathrm{D} / \mathrm{H}$ ratio which is already supported by many empirical examples (KAHRAMAN \& Cubukcu, 2017).

The term enclosure is described as an enclosed room like an outdoor space where the vertical elements like buildings create the enclosure. It is further said that buildings act as "walls" of the previously mentioned outdoor room. (Ewing \& Handy, 2009). This is also said that people can better understand the place and feel safe when they stay in an enclosed space in comparison with places where the sense of enclosure is weak (Stamps, 2005)

This is well established from the above discussion that enclosure should be provided in the welldesigned urban plaza. And to measure the enclosure $\mathrm{D} / \mathrm{H}$ ratio is used. To understand the argument of this paper, the following plaza conditions should be observed.
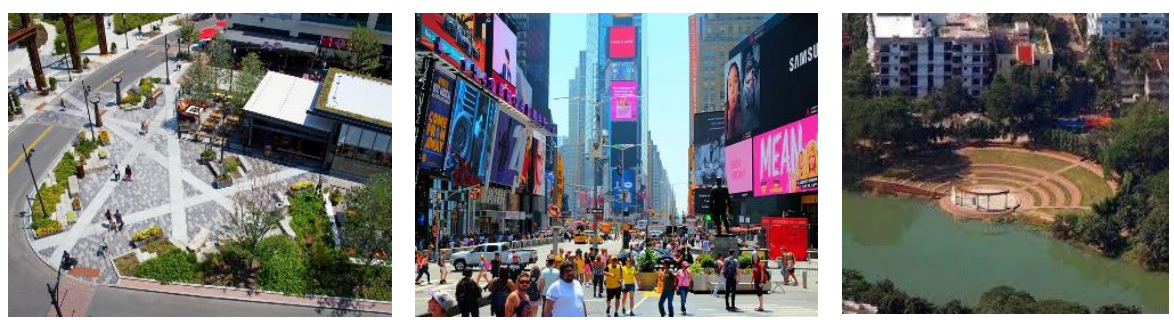

Figure 1, (left to right) the building is on only one side, voids are created by connecting road, and the plaza is defined by trees (source: Google) 


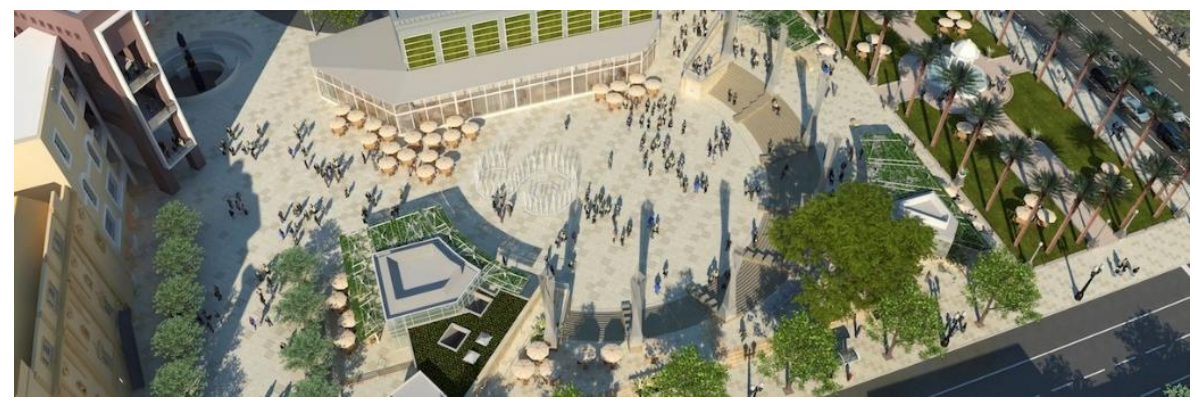

Figure 2, one side of the plaza is defined by trees (source: Google)

Though buildings are considered as the urban walls, this wall is perforated. It can be seen from the above-mentioned plazas that sometimes, all the sides are not occupied by buildings, connecting roads, voids between buildings, height variation of surrounding buildings, etc. can cause openness. From this observation, it can be said that the degree of the enclosure is also affected by the perforation of the surrounding enclosure, and this paper will map how the change in surrounding elevation impact the sense of openness of urban plazas in mathematical term

\section{Literature review:}

Different spaces perform different functionalities. Whether the design is successful or not can only be presumed by realizing its performance respecting that function. Such as, for any mosque, the more spiritual the prayer hall is the more successful the design is. Along with wonderful outdoor views and vistas, any bedroom should have more privacy and separation. So to detect relationship, a particular space and its judging criteria should be fixed. For this paper urban plaza-like space that accumulates public activities and performances is selected to study. A clear conception about welldesigned public squares are cited in "A pattern language: Towns Buildings construction" (Alexander, et al., 1977)

This is already said that the enclosure of the urban plaza is determined by the $\mathrm{D} / \mathrm{H}$ ratio, where $\mathrm{D}$ denotes the distance from the viewpoint to the surrounding elevation, and $\mathrm{H}$ denotes the height of surrounding building elevation. Then, the various ratio is assigned to mark different perception of enclosure of the plaza. When the ratio is 1:1 it means full enclosure, ratio 2:1 means threshold enclosure, 3:1 means minimum enclosure, and 4:1 means loss of enclosure (Spreiregen, 1965)Though this $\mathrm{D} / \mathrm{H}$ ratio is well accepted, this is argued that the sense of enclosure comprised of visual qualities such as openness, magnificence, and coziness, but the priority of the qualities depends on the context. The surrounding building elevations play a vital role in determining the qualities (Kim, 2017). Hillier cautioned that without understanding the context the enclosure shouldn't be used indiscriminately to avoid urban problems that can be associated with the wrong use of the enclosure. (Hillier, 1988)

From these arguments of the above-mentioned literature, it can be said that the enclosure must be determined based on context and the quality of the surrounding elevation is an important part of the consideration. This paper examined the quality of surrounding elevations by their degree of perforation and evaluated them to determine the openness of the plaza in relation with the $\mathrm{D} / \mathrm{H}$ ratio. Then, it can be argued that, whether the generalization of perception of space is acceptable or not as different people will have a different opinion. In this regard, it is said that perception presupposes a higher degree of complexity in gathering and processing information (POP, 2013). Despite deviations, we can surely generalize our perceptions. A south-facing veranda connected with a neighborhood road is certainly preferable to many. Many architects discovered these patterns and also generated new architectural languages to follow (Alexander, et al., 1977)This paper reveals a deeper investigation of our preferences by turning qualitative values of openness perceptions into quantitive. 
Now, It will be described from the literature, the usability of VR to determine the perceptual relations. The term 'virtual reality (VR)' refers to applications in which we can interact with spatial data in real-time. (Whyte, 2002)Those applications possess expressions of almost real-time experience that reduces the ambiguity we face in $2 \mathrm{D}$ screens. For this research VR box developed by Shinecon is used to create a head-mounted display. The Head-mounted display comprising two miniature display screens produces stereoscopic images. An optical position tracking system tracks the orientation of the observer's head in the Virtual world which matches his/her movement with the imported 360 images. A similar kind of experiment revealed that the use of VR in determining the enclosure of space (KAHRAMAN \& Cubukcu, 2017) . It is undeniable that current technologies regarding VR have many limitations in mimicking actual context. As the paper focuses more on the methodology of deriving an inter-relationship, it deals with ideal conditions at the primary level, while the future advancement of technology would enhance the accuracy of its implementation.

\section{Methodology:}

The methodology comprised of two steps: At first Step: different plaza conditions of varying values of $\mathrm{D}$ (radius of the plaza) and $\mathrm{H}$ (height of the boundary objects) were created where the perforation of the surrounding elevation was varied. At first, the surrounding perforation was zero and the value of $\mathrm{D}$ and $\mathrm{H}$ was changed gradually. Then the perforation of the surroundings was reduced by certain percentages and the $\mathrm{D} / \mathrm{H}$ ratio also changed gradually. Thus the variations of the plaza were produced using a parametric design tool called Grasshopper. Then 360-degree images of the plaza variations were prepared. After that, 32 respondents from an architectural school in Bangladesh had asked to rate them for openness after having a virtual journey using a head-mounted Virtual Reality (VR) display. Responses from experts, especially those who are connected with design studies may differ from the responses from non-designers as stated in (Avishag Shemesh, Moshe Bar, Yasha Jacob Grobman, 2015). This paper only focuses on the responses from participants associated with the architectural field.
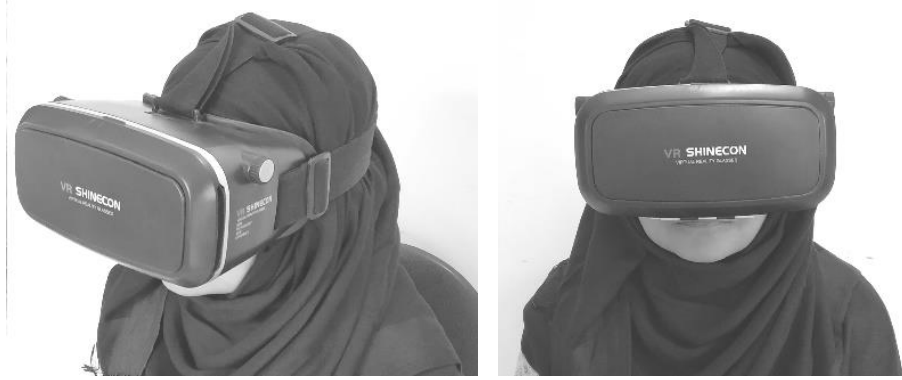

Figure 3, Participant experiencing generated spaces through VR box (source: Author)

Second Step: Using the responses an artificial Neural Network was trained to predict the openness of any plaza by providing its radius, height of the surrounding elevation, and the amount of perforation of the elevation. To do so, Lunchbox is used which is a plug-in of grasshopper which assists designers to use machine learning algorithms inside a software called Rhinoceros

\section{Environment Configuration:}

This openness factor simultaneously fluctuates with the changes of any space-defining parameter. Very often we perceive any space performing outmost usage of our sensory organs. A slighter change in the environment may render a different expression of the same space (POP, 2013). That's why to avoid complexity, the first task is to oversimplify the space configuration. An ideal space with a circular area, bounded by 10" brick walls with cloudless general sky condition, where bricks may help to comprehend the scale for the participants. The circular area is taken to specify it by one single parameter. The sun is placed in the south-west at $3.00 \mathrm{pm}$, casting sharp shadows over the ground. The position of the observer is marked red. Space between the experimental space and the horizon is colored white. The parametric space is generated in software Rhinoceros $3 \mathrm{D}$ with the help of a plug-in named Grasshopper. 


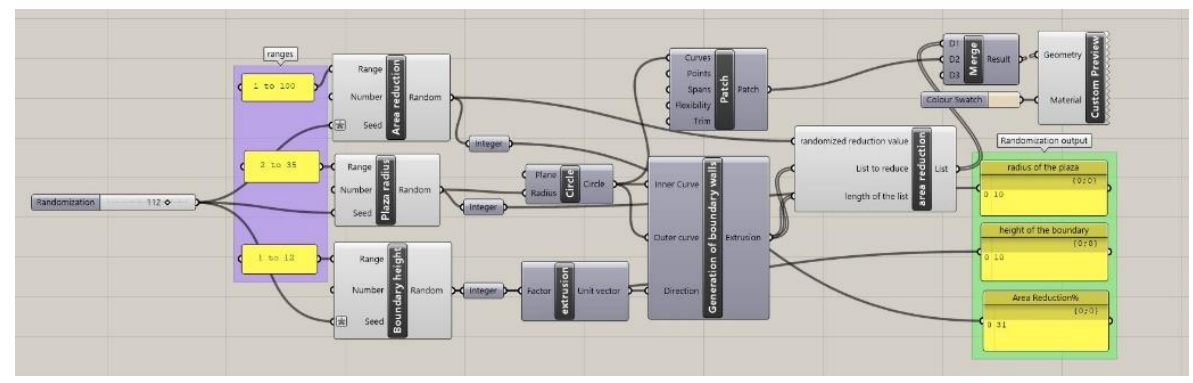

Figure 4, Script used to generate distinctive spaces of randomized values of three different parameters though Grasshopper (source: Author)

The outputs are visualized and exported as 360 images through another software named Lumion 8 . If the radius of the space in enlarged, space may gain more marks on openness. Again the increase of the height of the boundary walls renders more confinement. At the first stage, 70 different spaces of different wall height and radius were selected. Then respondents were exposed to have a virtual journey to plazas whose value of $\mathrm{D}$ and $\mathrm{H}$ are varied randomly. As both the highest radius and heights are $35 \mathrm{~m}$, they were asked not to rank more than 35, which may help to find out whether the relationship is linear or polynomial.
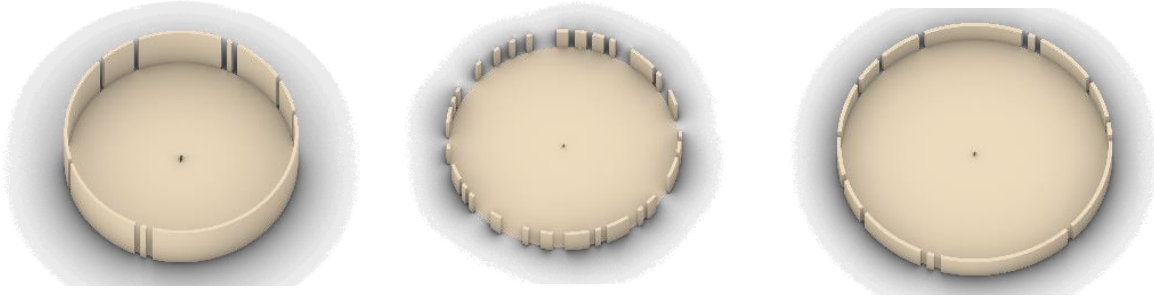

Figure 5, Three distinct spaces (left to right) Radius: 18m Height: 10m Area reduction: 7\%; Radius: 32m

Height: 07m Area reduction: 12\%, Radius: 34m Height: 09m Area reduction: 54\% (source: Author)

In the second stage, another parameter is added which marks exposure. The more area of the boundary wall will be reduced the more space will be dissolved. The area omitted is installed as another parameter and 110 different spaces were selected randomly. By following the previous method, now we will find a four-dimensional surface that identifies the relationship between openness, the radius of the area, height, and reduced area of the surrounding wall.
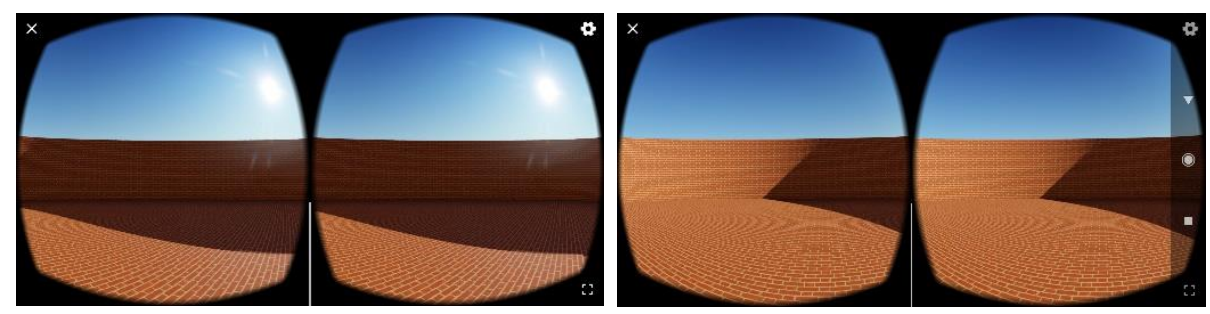

Figure 6, Virtual environment (no reduction of Area) displayed through smartphone screen (source: Author)

\section{Deduction of mathematical expression:}

\section{Step o1: Radius, height, and openness relationship:}

Non-linear Regression and Artificial Neural Network both can help us create a model that can generalize the data we get from surveying. In statistical modeling, regression analysis is a set of statistical processes to find out the relationships among the given variables. It includes many techniques for modeling and analyzing several variables. The main focus is on the relationship between a dependent variable and one or more independent variables. Here, openness is assumed 
to be as the dependent variable, and radius, the height of the walls are considered as independent variables. Regression analysis helps one understand how the typical value of the dependent variable changes when any one of the independent variables is varied, while the other independent variables are held fixed. (Linear-Regression, 2019)

First, all the survey data were imported in the software named rhinoceros 3D as individual points of which values of $\mathrm{x}, \mathrm{y}$, and $\mathrm{z}$ co-ordinates resemble the radius of the space, the height of the boundaries, and participants' response respectively. A plug-in named Lunchbox (by Nathan Miller) helped to generate a surface from the input data by non-linear regression. The generated surface expresses a generalized inter-relationship between the two parameters and the outcome. Any point on that surface (shown in the figure: 7 ) will expose the predicted outcome as the value its $\mathrm{Z}$ co-ordinates for the imported values of radius and height as the $\mathrm{X}$ and $\mathrm{Y}$ coordinates.
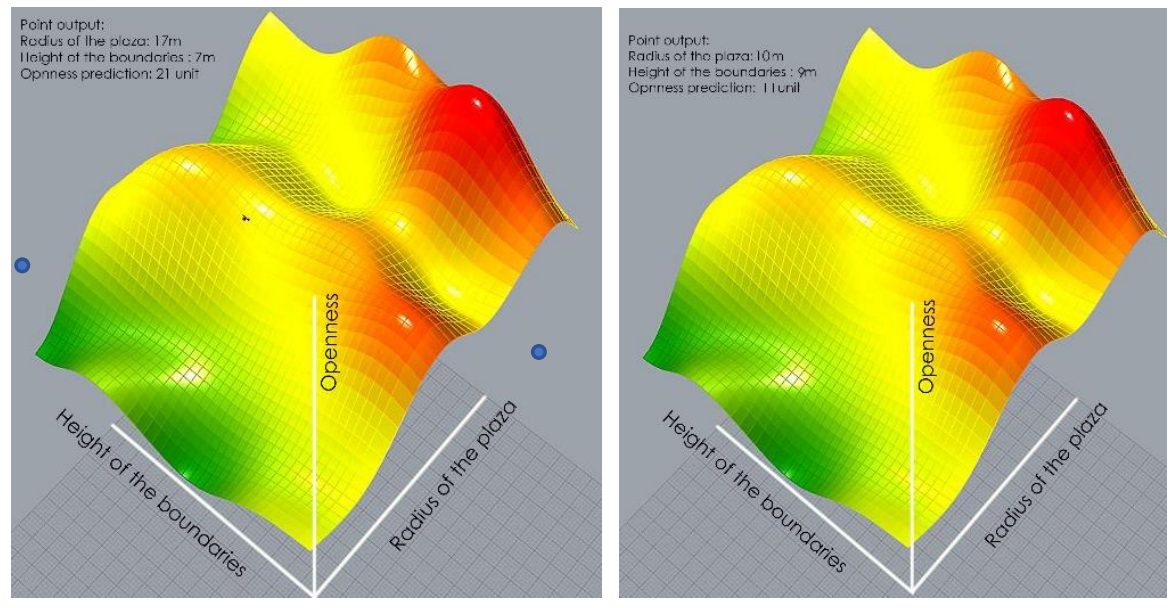

Figure 7, Prediction of openness by randomly asked values of radius and height (source: Author)

\section{Step o2: Radius, height, reduced area, and openness relationship:}

To add another parameter in defining the relationship Artificial Neural Network (ANN) is used. This model can provide a prediction of any given input. To capture the real-world complex relationship, we must include more data and more parameters and filter out the noise. A deeper neural network has the power to capture more complex relationships. The deep neural network has multiple layers of neural connectivity which helps to learn nonlinear relationships. (Artificial-neural-network, 2019)

In this stage, we generated 110 different spaces with different radius and height, where some portions of the boundary wall were removed randomly. The percentage of area reduced from the boundary is defined as the $3^{\text {rd }}$ parameter. Space with the same radius and height of the boundary wall will render different openness output respecting the amount of the space exposed outside. Here a software named 'Visual Gene Developer' (version 1.9) is used to find out the predicted outcome of any given value of all three parameters. Responses from the participants of randomly selected spaces were imported as training value. A set of predicted data were asked to provide, while the software trained itself with the imported data. For generalization, a small deviation is noticed between the given and predicted data, but this helped to render the bigger picture in the software Rhinoceros 3D. For a stationary input of the $3^{\text {rd }}$ parameter again a surface was generated by non-linear regression (following the process showed in figure 7) by importing the predicted values as $\mathrm{Z}$ coordinates of the individual points. Though this way, we can ask 'Visual Gene Developer' a set of predictions for any number of imported parameters, and by placing those prediction values in Rhinoceros $3 \mathrm{D}$ we can visualize their inter-relationship.

All the relationship surfaces obtained in the second phase is hard to express through one single image. With changes in the amount of reduced area, the relationship surface will acquire another formation. Here amongst all possible relationship status, 4 particular surfaces are shown to comprehend dependency of the outcome for changes in the $3^{\text {rd }}$ parameter. 

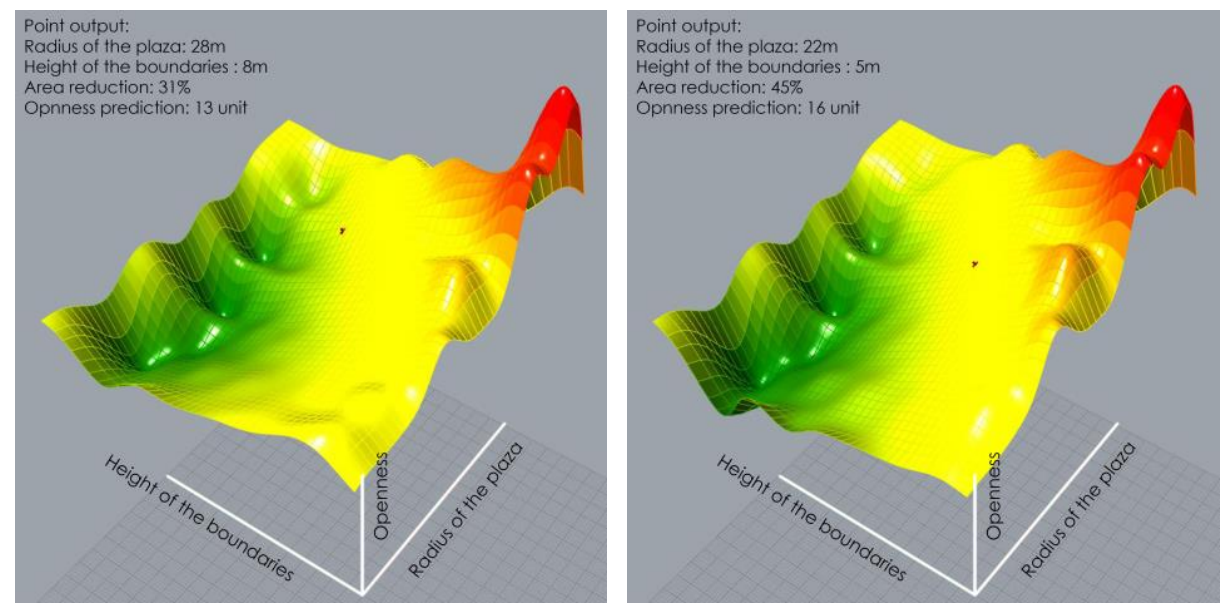

Figure 8, Prediction of openness by randomly asked values of radius and height for a fixed amount of Area reduction (source: Author)
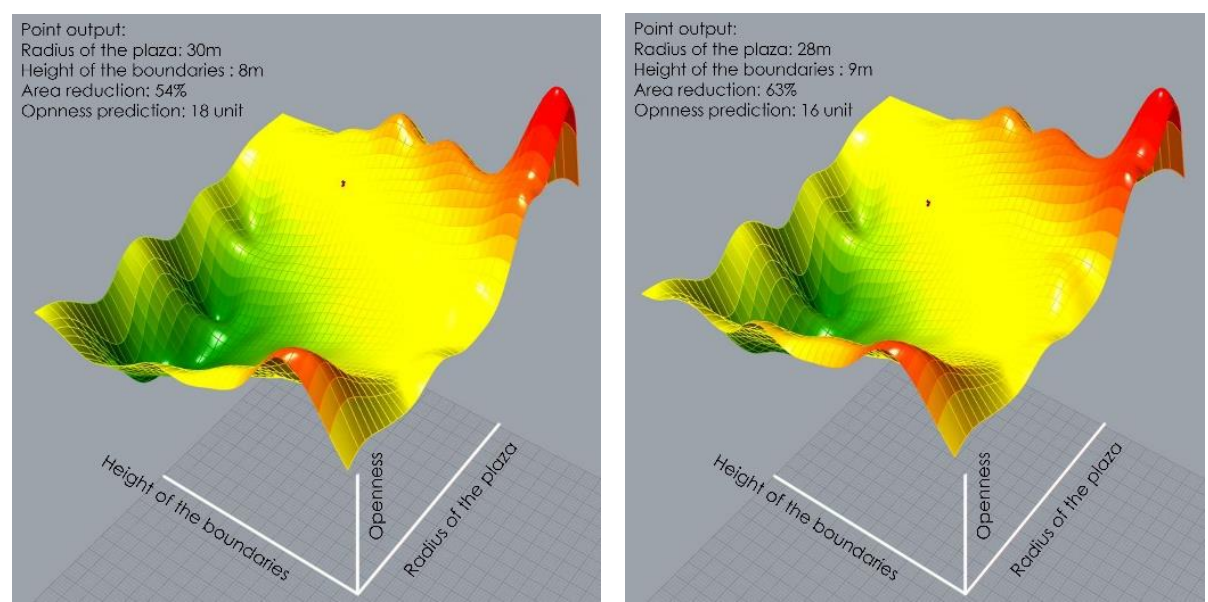

Figure 9, Prediction of openness by randomly asked values of radius and height for a fixed amount of Area reduction (source: Author)

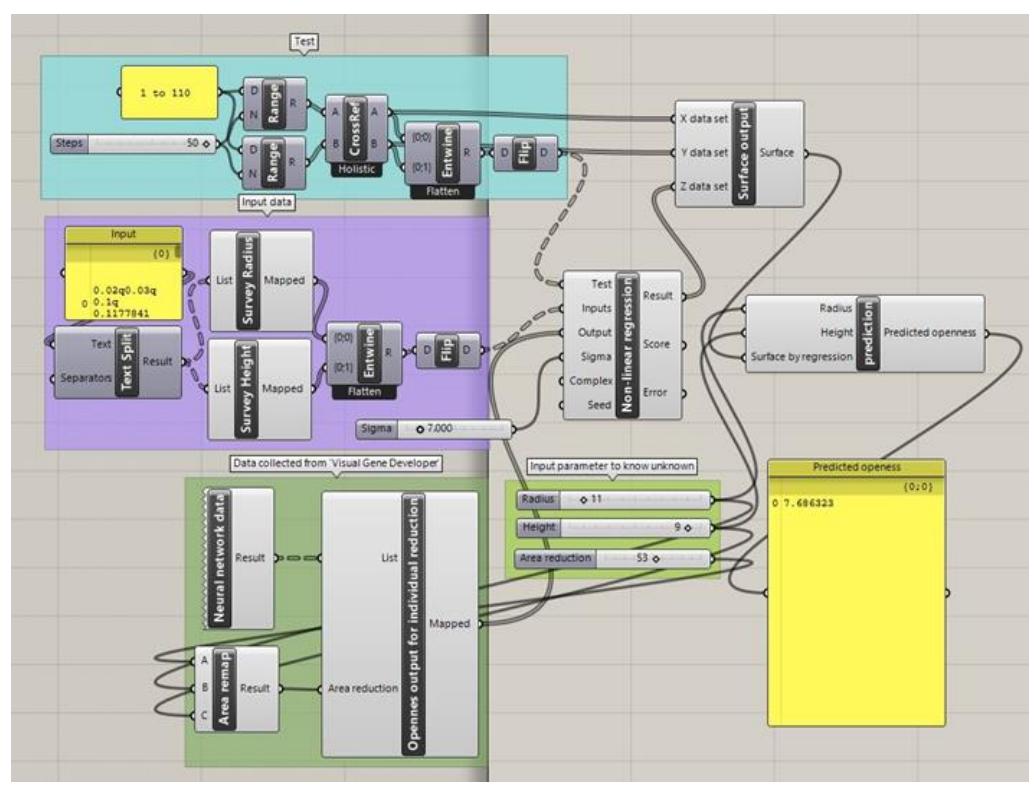

Figure 10, Scripts used in Grasshopper (a plug-in of Rhinoceros 3D) to predict openness by randomly asked values of radius, height, and percentage of area reduction (source: Author) 


\section{Discussions:}

There is two importance of the findings:

i)When the relation of radius, height, and openness was mapped, it was found that the solution surface is undulated, that means the relationship is non-linear among them and so, using the solution surface for determining the openness is more logical rather than the $\mathrm{D} / \mathrm{H}$ ratio. And when the perforation parameter was added, the solution surface was different for every particular amount of reduction, which means, for the same value of height and radius there are many possible values of openness is possible which satisfy the initial idea that varying the perforation will affect the sense of enclosure along with $\mathrm{D} / \mathrm{H}$ ratio.

ii) From the Artificial Neural Network, openness can be predicted. From the examples of the above, it was seen that by providing the configuration of radius, height, and reduction of mass the openness of the plaza was obtained. The grasshopper script for predicting the openness is in fig-9 and fig-10.

The openness is counted on a scale of 1 to 35 that can't give any absolute value. This scale was applied only to comprehend their inter-relationship. But, for generative design, if there are many iterations of the plaza, obviously this scale can help designers to comparatively understand the openness of the plaza. And any remapping of the scale is possible. So, it can be considered as a process of understanding space quality by measuring empirical data and applying machine learning algorithms to predict the unknowns where multiple parameters can be examined at a time. A simulator can be developed for the perception of the urban plaza from a human perspective after counting other parameters and combining them. This paper can be considered as an important document for it.

\section{Bibliography}

Alexander, C., Ishikawa, S. \& Silverstein, M., 1977. A Pattern Language. New york: Oxford University press. Anthony Webster,Steven Feiner,Blair MacIntyre, William Massie,Theodore Krueger, n.d. Augmented Reality in Architectural Construction, Inspection, and Renovation. s.l.:s.n.

Aoun, R. G., 2016. Emotional Design in Architecture. Architect and Urban Designer Consultant at SOLIDERE International, pp. 12-13.

Artificial-neural-network, 2019. Artificial neural network. [Online]

Available at: https://en.wikipedia.org/wiki/Artificial neural network

Basu, T. \& Ghosh, M., 2017. Visual Perception of Space and Parametric Design. GSTF Journal of Engineering

Technology (JET), p. 7.

Benoudjit, M. A. \& Derix, C., 2004. Human perception and space classification: The Perceptive Network. s.l., s.n., pp. 114.

Bertamini, Marco, Palumbo, Letizia, Gheorghes, Tamara and Galatsidas, Mai, 2015. Do observers like curvature or do they dislike angularity?. Sheffield Hallam University Research Archive (SHURA).

Ching, F. D., 2007. ARCHITECTURE Form, Space, Order. 3rd ed. s.l.:John Wiley \& Sons, Inc..

Claudia Perren, Miriam Mlecek, 2015. "PERCEPTION in Architecture. HERE and NOW. Berlin: Cambridge Scholars Publishing .

Colney, X., n.d. VIRTUAL REALITY. p. 6.

Dillard, J., Dujon, V. \& King, M. C., 2008. Understanding the Social Dimension of Sustainability. NewYork: s.n.

Dockx K, Bekkers EMJ, Van den Bergh V, Ginis P, Rochester L, Hausdorff JM, Mirelman A,Nieuwboer A, 2016. Virtual reality for rehabilitation in Parkinson's disease. s.l.:John Wiley \& Sons, Ltd..

Ewing, R. \& Handy, S., 2009. Measuring the Unmeasurable: Urban Design Qualities Related to Walkability. Journal of Urban design.

Hillier, B., 1988. Against enclosure. In Rehumanizing Housing. London: s.n.

KAHRAMAN, E. D. \& Cubukcu, E., 2017. Developing The Standards For Sense of Enclosure: An Experimental Study in Virtual Environments. Istanbul, Turkey, CPUD 17 International City Planning and Urban Design Conference.

Kieferle, J. a. W., 2001. Showing the invisible. Seven rules for a new approach of using immersive virtual reality in architecture. 19th eCAADe Conference, pp. 376-381.

Kim, J., 2017. Comparing the Influences of the D/H Ratio.

Kruft, H.-W., 1994. A history of architectural theory : from Vitruvius to the present. London : Princeton Architectural Press.

Linear-Regression, 2019. Linear regression. [Online]

Available at: https://en.wikipedia.org/wiki/Linear_regression

Liu, C., 2013. Research on scale of urban squares in Copenhagen, Sweden: Blekinge Institute of Technology.

MA, W. R. \&. A., 2004. Aesthetics and Architectural Composition. proceedings of the Dresden International Symposium of Architecture.

Mehul Bhatt, C. H. T. F. S. (., 2011. Spatial Cognition for Architectural Design. SCAD Symposium, pp. 1-270. POP, D., 2013. Space Perception and Its Implication in Architectural Design. Acta Technica Napocensis: Civil Engineering \& Architecture, Volume 56, p. 11.

Shemesh, A., Bar, M. \& Jacob;, G. Y., 2015. Space and Human Perception. International Conference of the Association for Computer-Aided Architectural Design Research in Asia CAADRIA, pp. 1-10. 
Spreiregen, P. D., 1965. The architecture of towns and cities. s.l.:McGraw-Hill.

Stamps, A., 2005. Elongation and enclosure. Perceptual and motor skills,, s.l.: s.n.

Thiel, P., 1961. A Sequence-Experience Notation: For Architectural and Urban Spaces. s.l.:Liverpool University Press. Virtual_reality, 2019. [Online]

Available at: https://en.wikipedia.org/wiki/Virtual_reality

Whyte, J., 2002. Virtual Reality and the Built Environment. Oxford: Architectural Press. 